\section{The Crystal Structure of $\beta$-CsIO the Room-Temperature Modification of Cesium Periodate}

Danita de Waal*, Manfred Zabel, Klaus-Jürgen Range**

Institute of Inorganic Chemistry, University of Regensburg, Universitätsstraße 31, D-93053 Regensburg

Z. Naturforsch. 51 b, $441-443$ (1996); received July 17, 1995

Cesium Periodate, Room-Temperature Modification, Crystal Structure

The crystal structure of $\beta-\mathrm{CsIO}_{4}$, the room-temperature modification of cesium periodate, was determined as orthorhombic, space group Pnma, with $a=5.8644(5), b=6.0326(4), c=14.379(1) \AA$ and $Z=4$.

The structure was refined to $R_{1}=0.0309, w R_{2}=$ 0.0701 for 425 absorption-corrected reflections. $\beta-\mathrm{CsIO}_{4}$ is isostructural with $\beta-\mathrm{CsReO}_{4}$. The structure comprises isolated $\mathrm{IO}_{4}$ tetrahedra, linked together by $\mathrm{Cs}$ ions. The average I-O distance was found to be $1.747 \AA$.

The temperature-dependent polymorphism of $\mathrm{CsIO}_{4}$ was investigated by means of Ramanspectroscopy [1-3], thermal analysis [4-6], compressibility measurements $[7,8],{ }^{133} \mathrm{Cs} /{ }^{127} \mathrm{I}-\mathrm{NMR}$ spectroscopy [9], ${ }^{127}$ I-NQR-spectroscopy [9,10] and adiabatic calorimetry [11]. It was found that $\mathrm{CsIO}_{4}$ has at least three modifications $(\alpha, \beta, \delta)$, perhaps even a fourth one $(\gamma)$, with the following transformation temperatures:

$\delta-\mathrm{CsIO}_{4} \underset{287 \mathrm{~K}}{\rightleftarrows} \gamma-\mathrm{CsIO}_{4}(?) \underset{291 \mathrm{~K}}{\rightleftarrows} \beta-\mathrm{CsIO}_{4} \underset{423 \mathrm{~K}}{\rightleftarrows} \alpha-\mathrm{CsIO}_{4}$

The structural situation is, however, not yet clear. One reason is the high sensitivity of $\mathrm{CsIO}_{4}$ crystals to X-rays, which causes broadening or even complete disappearing of the reflections during long-time exposure at structure determinations. There are, of course, speculations about the space groups and structure types for the different modifications [12], but no complete crystal struc-

* Permanent address: Department of Chemistry, University of Pretoria, Pretoria 0002, South Africa.

** Reprint requests to Dr. Danita de Waal or Prof. Dr. K.-J. Range. ture analysis has been reported for any of the $\mathrm{CsIO}_{4}$ modifications up to now.

For $\beta$ - $\mathrm{CsIO}_{4}$, the room-temperature modification of cesium periodate, Beintema [13] determined the positions of the heavy atoms in an orthorhombic unit cell and proposed that the compound should be isotypic with $\beta-\mathrm{CsReO}_{4}$ in the so-called pseudoscheelite structure. However, exact coordinates for the oxygen atoms could not be derived by Beintema due to the limitations of the film methods used by him and due to the general problems mentioned above.

Recently, we refined the crystal structure of $\beta$ $\mathrm{CsReO}_{4}$, the room-temperature modification of cesium perrhenate [14]. To check the proposed structural relations between $\beta-\mathrm{CsIO}_{4}$ and $\beta$ $\mathrm{CsReO}_{4}$ we decided to reinvestigate the crystal structure of the former again. The problems cre-

Table I. Crystal data, data collection and refinement parameters for $\beta$-CsIO ${ }_{4}{ }^{\mathrm{a}}$.

\begin{tabular}{ll}
\hline Formula & $\mathrm{CsIO}_{4}$ \\
Molecular weight & $323.81 \mathrm{~g} \cdot \mathrm{mol}^{-1}$ \\
Space group & Pnma $(\mathrm{Nr} .62)$ \\
Cell dimensions & $a=5.8644(5) \AA$ \\
& $b=6.0326(4) \AA$ \\
& $c=14.379(1) \AA$ \\
$Z$ & $\mathrm{~V}=508.69(5) \AA^{3}$ \\
$Z$ & $4.228 \mathrm{~g} \cdot \mathrm{cm}^{-3}$ \\
Density (calcd) & $13.24 \mathrm{~mm}^{-1}$ \\
$\mu($ MoK $\alpha)$ & 560 \\
F(000) & $298(1) \mathrm{K}^{-3}$ \\
Temperature & $\mathrm{STOE} \mathrm{IPDS}$ \\
Diffractometer & $\mathrm{MoK} \alpha(\lambda=0.71073 \AA)$ \\
Radiation & $80 \mathrm{~mm}$ \\
Detector distance & Oscillation \\
$\varphi$ movement mode & $1.0^{\circ}$ \\
$\varphi$ increments & 180 \\
Number of exposures & $1.0 \mathrm{~min}$ \\
Irradiation/exposure & $-6 \leq h \leq 6 ;-6 \leq k \leq 6 ;$ \\
$h k l$-limits & $-16 \leq l \leq 16$ \\
& 0.57 \\
(sin $\theta / \lambda)_{\text {max }}$ & 2833 \\
Recorded reflections & $425,0.1236$ \\
Unique reflections, $R_{\text {int }}$ & 35 \\
Parameters refined & $0.000,0.000 \AA$ \\
Mean shift/esd, max. shift & $0.0309,0.0701,1.086$ for all data \\
Final $R 1, w R 2, \mathrm{~S}$ & $+1.74,-0.99 \mathrm{e} \cdot \AA$ \\
$(\Delta \varrho$ ) max,min & $0.0088(7)$ \\
Extinction factor & \\
\hline
\end{tabular}

a Here, as in the following tables, the standard deviations are given in parentheses. 


\begin{tabular}{lllll}
\hline Atom & $x / a$ & $y / b$ & $z / c$ & $\mathrm{U}_{\text {eq }}$ \\
\hline Cs & $0.01955(10)$ & $3 / 4$ & $0.12777(2)$ & $0.0354(3)$ \\
I & $0.03230(12)$ & $1 / 4$ & $0.38056(3)$ & $0.0305(3)$ \\
$\mathrm{O}(1)$ & $0.8157(9)$ & $1 / 4$ & $0.0803(3)$ & $0.050(2)$ \\
$\mathrm{O}(2)$ & $0.8466(10)$ & $1 / 4$ & $0.4755(3)$ & $0.080(2)$ \\
$\mathrm{O}(3)$ & $0.0142(7)$ & $0.5105(7)$ & $0.6845(3)$ & $0.071(2)$ \\
\hline
\end{tabular}

Table II. Atomic positional parameters and displacement factors $\left[\AA^{2}\right]$ for $\beta-\mathrm{CsIO}_{4}$. Fractional atomic co-ordinates and equivalent isotropic displacement parameters ${ }^{\mathrm{a}}$.

Anisotropic displacement factors

\begin{tabular}{lllllll}
\hline Atom & $\mathrm{U}_{11}$ & $\mathrm{U}_{22}$ & $\mathrm{U}_{33}$ & $\mathrm{U}_{12}$ & $\mathrm{U}_{13}$ & $\mathrm{U}_{23}$ \\
\hline Cs & $0.0396(4)$ & $0.0345(5)$ & $0.0321(4)$ & 0 & $-0.0047(2)$ & 0 \\
I & $0.0309(5)$ & $0.0309(5)$ & $0.0298(4)$ & 0 & $0.0019(2)$ & 0 \\
$\mathrm{O}(1)$ & $0.044(4)$ & $0.048(4)$ & $0.058(3)$ & 0 & $0.012(2)$ & 0 \\
$\mathrm{O}(2)$ & $0.070(5)$ & $0.109(6)$ & $0.062(3)$ & 0 & $0.039(3)$ & 0 \\
$\mathrm{O}(3)$ & $0.081(3)$ & $0.059(4)$ & $0.074(3)$ & $0.020(3)$ & $-0.003(2)$ & $0.027(2)$ \\
\hline
\end{tabular}

a $\mathrm{U}_{\mathrm{eq}}$ is defined as one third of the trace of the orthogonalized $\mathrm{U}_{\mathrm{ij}}$ tensor. ated by the sensitivity of the $\mathrm{CsIO}_{4}$ crystals at extended exposure to X-rays could be overcome by using an Imaging Plate Diffraction System for data collection.

Cesium periodate was synthesized by neutralization of orthoperiodic acid, $\mathrm{H}_{5} \mathrm{IO}_{6}$ (Merck, p.a.) with cesium carbonate (Fluka, p.a.). The precipitated salt was purified by several recrystallizations from water. Single crystals were obtained by slow evaporation of a saturated aqueous solution of $\mathrm{CSIO}_{4}$ at ambient temperature in air.

Gandolfi- and X-ray powder patterns showed the identity of single crystals and bulk material. The powder pattern (recorded on a Stoe Stadi-P diffractometer, using $\mathrm{CuK} \alpha_{1}$ radiation and a linear position-sensitive detector) could readily be indexed with the IP lattice parameters as starting values for the refinement [15]. Because of their better accuracy, these refined values of the lattice parameters (given in Table I) have been retained for the calculation of atomic distances and bond angles.

Table III. Selected interatomic distances $[\AA]$ and bond angles $\left[{ }^{\circ}\right]$.

\begin{tabular}{|c|c|c|c|}
\hline $\begin{array}{c}\mathrm{I}-\mathrm{O}(3) \\
-\mathrm{O}(2) \\
-\mathrm{O}(1) \\
<\mathrm{I}-\mathrm{O}>\end{array}$ & $\begin{array}{l}1.743(4) \\
1.746(5) \\
1.755(5) \\
1.747(5)\end{array}$ & $\begin{array}{l}\mathrm{O}(1)-\mathrm{I}-\mathrm{O}(2) \\
\mathrm{O}(1)-\mathrm{I}-\mathrm{O}(3) \\
\mathrm{O}(2)-\mathrm{I}-\mathrm{O}(3) \\
\mathrm{O}(3)-\mathrm{I}-\mathrm{O}(3)\end{array}$ & $\begin{array}{ll}109.9(2) & \\
108.7(2) & (2 \times) \\
108.8(2) & (2 \times) \\
112.0(3) & \end{array}$ \\
\hline $\begin{array}{c}\mathrm{Cs}-\mathrm{O}(2) \\
-\mathrm{O}(3) \\
-\mathrm{O}(1) \\
-\mathrm{O}(3) \\
-\mathrm{O}(1) \\
-\mathrm{O}(3) \\
\langle\mathrm{Cs}-\mathrm{O}>\end{array}$ & $\begin{array}{ll}3.066(5) & \\
3.129(3) & (2 \times) \\
3.144(4) & \\
3.258(4) & (2 \times) \\
3.316(2) & (2 \times) \\
3.281(4) & \end{array}$ & $\begin{array}{l}\mathrm{I}-\mathrm{Cs} \\
-\mathrm{Cs} \\
-\mathrm{Cs}\end{array}$ & $\begin{array}{ll}4.157(0) & (2 \times) \\
4.261(0) & (2 \times) \\
4.421(1) & \end{array}$ \\
\hline
\end{tabular}

A colourless transparent crystal (approx. dimensions $0.08 \times 0.08 \times 0.08 \mathrm{~mm}$ ) was selected for the $\mathrm{X}$-ray investigations. Data collection was performed on a Stoe-IPDS Imaging Plate Diffraction System using $\mathrm{MoK} \alpha$ radiation (graphite monochromator in incident beam); for experimental details, see Table I. After reduction of the 2833 recorded data a set of 425 independent reflections (363 with $F_{o} \geqslant 4\left(F_{o}\right)$ ) remained of which all were used in the subsequent calculations. Crystallographic and experimental data are summarized in Table I.

Systematic absences of the type $(0 k l): l+k=$ $2 n+1$ and $(h k 0): h=2 n+1$ were observed, agreeing with space groups Pnma and $\mathrm{Pn} 2{ }_{1}$ a. The results of the structure refinement confirmed the centrosymmetric space group Pnma.

All calculations were carried out using the programs SHELXS-86 amd SHELXL-93 [16]. The structure was solved by Patterson methods, followed by successive difference Fourier syntheses. After isotropic refinement a numerical correction for absorption was applied to the original data set (Program DIFABS, [17]). The final full-matrix least-squares refinement on $\mathrm{F}^{2}$ (including anisotropic displacement factors and an extinction factor) converged at $w R_{2}=0.0701, R_{1}=0.0309$ for all 425 data. Atomic positions and displacement factors for $\beta-\mathrm{CsIO}_{4}$ are given in Table II, derived atomic distances and angles in Table III*.

\footnotetext{
* Further details of the crystal structure determination can be obtained from the Fachinformationszentrum Karlsruhe GmbH, D-76344 Eggenstein-Leopoldshafen, by quoting the depository number CSD 59082.
} 
The crystal structure of $\beta-\mathrm{CsIO}_{4}$ comprises isolated $\mathrm{IO}_{4}$ tetrahedra which are linked together by cesium ions. The average I-O distance was found to be $1.747(5) \AA$. Cesium ist tenfold coordinated by oxygen with an average Cs-O distance of 3.281(4) A. The present single-crystal study confirms the space group and the positional parameters of the heavy atoms for $\beta-\mathrm{CsIO}_{4}$, as proposed by Beintema [13]. $\beta$ - $\mathrm{CsIO}_{4}$ is indeed isomorphous with $\beta$-CsReO ${ }_{4}$ [14], as well as with $\mathrm{CsTcO}_{4}$ [18] and $\mathrm{RbOsO}_{3} \mathrm{~N}$ [19]. It represents an orthorhombic distortion of the tetragonal high-temperature structure of $\alpha-\mathrm{CsReO}_{4}$ and is topologically related to the scheelite type as well [20].

\section{Acknowledgements}

The generous support given by the Fonds der Chemischen Industrie is gratefully acknowledged. Danita de Waal thanks the Alexander-von-Humboldt Foundation for a Research Fellowship.
[1] T.A. Al-Dhahir, B. Raghunatha Chary, H.L. Bhat, P.S. Narayanan, Ind.J. Pure Appl.Phys. 26, 239 (1988).

[2] T.A. Al-Dhahir, G. Raghurama, H.L. Bhat, Ferroelectr. Lett. 8, 49 (1988).

[3] T.A. Al-Dhahir, A.K. Sood, H.L. Bhat, Solid State Commun. 70, 863 (1989).

[4] H. Arend, H. Gränicher, R. Hofmann, Helv.Phys. Acta 43, 484 (1970).

[5] T.A. Al-Dhahir, G. Dhanaraj, H.L. Bhat, J.Crystal Growth 121, 132 (1992).

[6] C.A. Strydom, L.C. Prinsloo, Thermochim.Acta, submitted.

[7] P.W. Bridgman, Proc.Am.Acad. 71, 446 (1935/36).

[8] P.W. Bridgman, Proc.Am.Acad. 72, 113 (1936/37).

[9] V.P. Tarasov, G.A. Kirakosian, Yu.A. Buslaev, U. Eichhoff, Z.Phys.B - Condensed Matter 79, 101 (1990).

[10] P.K. Burkert, Z.Naturforsch. 35b, 1349 (1980).

[11] K.S. Gavrichev, V.E. Gorbunov, L.N. Golushina, V.P. Tarasov, Yu.K. Gusev, Russ.J.Phys.Chem. 64, 1202 (1990).
[12] H.L. Bhat, S.M. Clark, A. El Koravsky, K.J. Roberts, Report DL/SCI/P-673 E. Daresbury, 1989.

[13] J. Beintema, Z.Kristalllogr. 97, 300 (1937).

[14] K.-J. Range, P. Rögner, Z.Naturforsch. 48b, 685 (1993).

[15] The evaluted powder pattern of $\beta-\mathrm{CsIO}_{4}$ has been deposited with JCPDS-ICDD and can be obtained from the authors (K.-J. R.) as well.

[16] G.M. Sheldrick, SHELX-86. A Program for Crystal Structure Solution. Univ. Göttingen (1986); G.M. Sheldrick, SHELXL-93. Program for Structure Refinement. Univ. Göttingen (1993).

[17] N. Walker, D. Stuart, Acta Crystallogr. A39, 158 (1983).

[18] G. Meyer, R. Hoppe, Z. Anorg. Allg. Chem. 420, 40 (1976).

[19] P.L'Haridon, R. Pastuszak, Y. Laurent, J. Solid State Chem. 43, 29 (1982).

[20] K.-J. Range, R. Rögner, A.M. Heyns, L.C. Prinsloo, Z.Naturforsch. 47b, 1513 (1992). 